\title{
JOGO DIDÁTICO COMO FERRAMENTA PARA EDUCAÇÃO AMBIENTAL NO MUNICÍPIO DE ITAPETINGA (BA)
}

\author{
Isiara Silva Menezes ${ }^{1}$ \\ Stephanio Henning Silva de Freitas ${ }^{2}$ \\ Patrícia Abreu de Araújo Cara ${ }^{3}$ \\ Ana Paula Lima do Couto-Santos ${ }^{4}$
}

Resumo: Este estudo propôs uma intervenção ambiental para esclarecer sobre as potencialidades e problemas enfrentados pela mata ciliar do Rio Catolé no município de Itapetinga (BA). A pesquisa foi desenvolvida com 06 turmas do $3^{\circ}$ ano do Ensino Médio de uma Unidade de Ensino do município. Métodos: i) aula sobre o conteúdo "Mata ciliar do Rio Catolé: problemas e potencialidades"; ii) aplicação do jogo "Reconquista da Mata Ciliar"; iii) questionários. Verificou-se um aumento no conhecimento após a intervenção ambiental. Este trabalho pode auxiliar: i) Programas de reflorestamento na APP "mata ciliar do Rio Catolé"; ii) Educação Ambiental na Mata Ciliar do Rio Catolé e iii) Projetos políticos pedagógicos que visem conscientizar a respeito dessa temática.

Palavras-chave: Mata Ciliar, Estratégia Educativa, Ensino-Aprendizagem, Rio Catolé.

\footnotetext{
${ }^{1}$ Universidade Estadual de Feira de Santana. E-mail: isiarabio@gmail.com

2 Faculdade Pitágoras. E-mail: stephaniohenning@hotmail.com.

3 Universidade Estadual do Sudoeste da Bahia. E-mail: patycara@yahoo.com.br.

4 Universidade Estadual do Sudoeste da Bahia. E-mail: aplcouto@yahoo.com.br.
} 


\section{Introdução}

No decorrer da história, sobretudo após a revolução industrial, o homem vem agindo sobre a natureza não só pelo seu sustento, mas para acumular bens e obter lucro. E a riqueza, gerada por esse ritmo de exploração desenfreado do meio ambiente, não impede o aumento da miséria e da fome, mas sim traz graves consequências para humanidade, por exemplo, o esgotamento do solo, a contaminação da água e a crescente violência nos centros urbanos (BRASIL, 1997, p.174; OLIVEIRA et al., 2007, p.472).

No Brasil, o processo de ocupação caracterizou-se pela falta de planejamento e destruição dos recursos naturais, particularmente das florestas nativas que foram sendo fragmentadas e cederam espaços para as culturas agrícolas, as pastagens e as cidades (PAZ; FARIAS, 2008, p. 287, 2001).

As florestas brasileiras possuem alto índice de endemismo e biodiversidade do planeta, e as bacias hidrográficas são detentoras de um número de espécies de peixes e de répteis inexistentes em qualquer outro lugar do mundo (LEANDRO; VIVEIROS, 2003). Nesse quesito, as matas ciliares ganham destaque, pois são essenciais para proteção dos recursos hídricos, já que atuam como uma barreira natural, protegendo os rios, servindo de filtro, mantendo a qualidade e a quantidade das águas, e protegendo os terrenos que ficam às suas margens (BAHIA, 2000). Além disso, de acordo com o Código Florestal (Lei no 4.777/65), as Matas Ciliares estão inclusas na categoria de áreas de preservação permanente (APP's). Por isso, toda área no entorno de nascentes de reservatórios, natural ou arbórea, devem ser conservadas (BAHIA, 2007; BITTENCOURT; BATISTA, 2009).

No entanto, mesmo com a mata ciliar exercendo todas essas importantes funções ecológicas, no Brasil, ainda existe o desrespeito ao meio ambiente, sobretudo quando isto está relacionado à flora que continua sendo devastada pelas queimadas, pelo corte desmedido de árvores, pela expansão das fronteiras agrícolas e pecuárias. Sendo assim, torna-se necessário algumas ações prioritárias respaldadas na legislação que venha proteger a mata ciliar com intuito de refrear a exploração indiscriminada das florestas e das outras formas de vegetação (LEANDRO; VIVEIROS, 2003).

O município de Itapetinga (BA) possuía uma vegetação exuberante de Mata Atlântica, porém devido à exploração contínua essa paisagem foi sendo substituída pela agropecuária e suas árvores de lei comercializadas (OLIVEIRA, 2013).

No Rio Catolé, situado em Itapetinga, a degradação da vegetação nativa causada pela pressão antrópica associada ao modelo de expansão agrícola estimula ainda mais os avanços das lavouras e pastos em direção aos biomas e consequente destruição da biodiversidade. Segundo Bonfim (2013), no Rio Catolé ainda existem alguns fragmentos remanescentes de mata ciliar, fazendo-se necessário que sejam conservados e 0 seu entorno seja recuperado, buscando uma sustentabilidade ambiental e social. 
Nesse contexto, educar para a cidadania é uma maneira eficaz de motivar o indivíduo a buscar melhoria na qualidade de vida e por meio da Educação Ambiental (EA) firmar o compromisso de promover a sustentabilidade (ALVES et al., 2012). O espaço escolar constitui um local privilegiado para o desenvolvimento da $E A$, já que visa formar cidadãos participantes da sociedade, conhecedor dos seus problemas e necessidades, bem como, sujeitos conscientes, preparados para exercer a cidadania, com aptidão para decidir e atuar na realidade socioambiental (SACRAMENTO et al., 2008).

A utilização de jogos didáticos (JD) como atividade lúdica no processo educativo pode ser uma importante ferramenta para o desenvolvimento da consciência ambiental, já que promove a aprendizagem, proporciona um espaço para o estabelecimento da responsabilidade individual e coletiva, desenvolve a iniciativa, e faz com que os indivíduos aprendam obedecer as regras, questioná-las e até mesmo recriá-las, revolucionando o espaço escolar (FORTUNA, 2003; MENEZES, 2012).

Dessa forma, na tentativa de formar cidadãos conscientes, críticos, preparados para transformar a realidade local através da conscientização ambiental, esse trabalho propôs uma intervenção no ambiente escolar para esclarecer aos estudantes sobre as potencialidades e problemas enfrentados pela mata ciliar do Rio Catolé na zona urbana de Itapetinga (BA).

\section{Material e Métodos}

O presente estudo realizou uma intervenção ambiental por meio de uma palestra, juntamente com a elaboração e confecção de um jogo educativo com intuito de esclarecer a comunidade escolar sobre as potencialidades e problemas enfrentados pela mata ciliar do Rio Catolé na zona urbana de Itapetinga, e a partir da análise de dados promover soluções práticas para melhoria da Educação Ambiental no município. Este trabalho caracteriza-se como uma pesquisa aplicada, exploratória, descritiva com abordagem qualitativa e quantitativa.

A pesquisa foi desenvolvida em 6 (seis) turmas do $3^{\circ}$ ano do Ensino Médio de uma Unidade de Ensino da rede pública estadual do município de Itapetinga (BA), onde a quantidade de alunos por turma variou de 30 a 40.

O desenvolvimento da metodologia foi divido em quatro momentos:

(1) Aplicação do Primeiro questionário: foi aplicado o questionário a uma amostra não probabilística por conveniência de discentes da turma que consentiram com a realização da pesquisa e que compareceu a escola no dia da coleta de dados. O questionário foi baseado no conteúdo "Mata Ciliar do Rio Catolé: problemas e potencialidades", e possui questões mistas, ou seja, abertas e fechadas. De cada turma foram escolhidos aleatoriamente questionários de 10 indivíduos para serem analisados; 
(2) Palestra: a pesquisadora ministrou uma palestra sobre o conteúdo "Mata Ciliar do Rio Catolé, Itapetinga (BA): problemas e potencialidades".

(3) Aplicação do Jogo "Reconquista da Mata Ciliar": "Reconquista da Mata Ciliar" é um jogo de regras que cobra estratégia e conhecimento específico dos participantes. Pode ser jogado em dupla ou em grupo, funciona basicamente como um jogo de conquista de território composto de um tabuleiro quadrangular, com 40 casas e para cada casa relaciona-se uma carta pergunta do tema (Figura 1). O jogo foi apresentado aos estudantes depois da palestra ministrada pela pesquisadora e sua elaboração foi condizente ao conteúdo ambiental trabalhado na palestra e ao público alvo.

(4) Após a aplicação do jogo foi entregue um novo formulário com as mesmas questões do questionário anterior para que os estudantes respondessem novamente.

Os questionários respondidos pelos discentes foram interpretados a partir da análise temática do conteúdo, seguindo a metodologia proposta por Caregnato e Mutti (2006). Assim, foi avaliando se houve mudança na percepção dos discentes em relação às potencialidades e problemas enfrentados pela mata ciliar do Rio Catolé na zona urbana de Itapetinga (BA), após a intervenção no ambiente escolar.

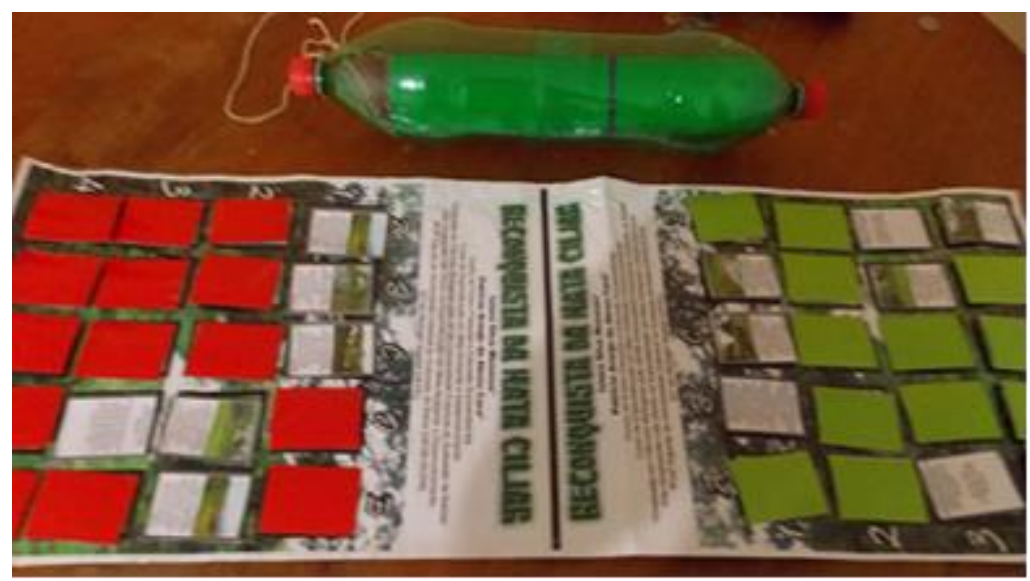

Figura 1: Jogo Didático "Reconquista da Mata Ciliar"; Tabuleiro com cartas, bolsa manufaturada com garrafas pet. Fonte: Autoria Própria.

\section{Resultados e discussão}

A Intervenção Ambiental realizada nesse estudo alcançou o objetivo dessa pesquisa e em todas as etapas foram perceptíveis o envolvimento dos estudantes, sendo possível obter ótimos resultados por meio da participação de todos que demostraram muito interesse na execução da pesquisa (Figura 2). 


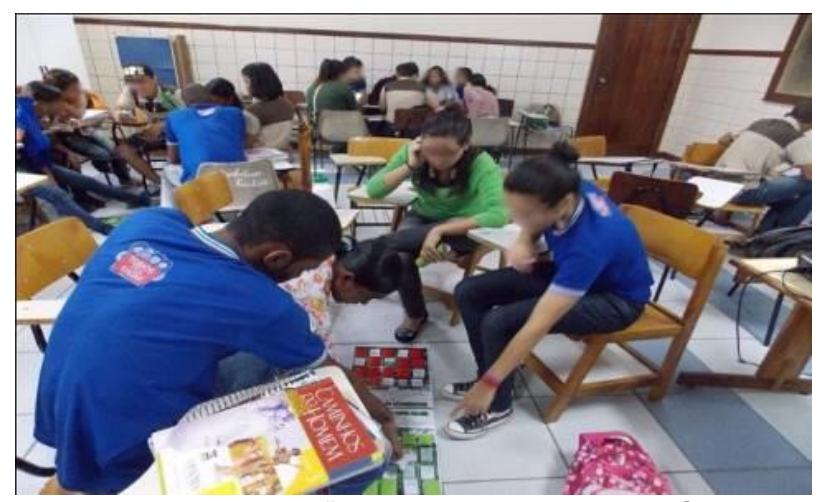

Figura 2: Aplicação do Jogo "Reconquista da Mata Ciliar" após a Palestra.

Fonte: Autoria Própria.

Silva e Grillo (2009, p.234) defendem que a utilização de JD na prática educativa serve como uma opção de diversão, auxilia na construção de conhecimento, proporciona o crescimento e o desenvolvimento intelectual, favorecendo a aprendizagem. Conforme esses autores, promover a EA, por meio de JD possibilita ao educando a participação do jogador no diagnóstico dos problemas ambientais e na busca de soluções para os mesmos, estimulando a tomada de consciência, bem como, uma conduta ética frente às questões ambientais com base em seu aprendizado durante a jogada.

Os resultados obtidos por meio da análise dos questionários corroboram com a afirmativa dos autores citados acima, uma vez que foi verificada uma diferença significativa na percepção dos discentes depois da IA.

Tanto antes quanto após a IA a maioria dos estudantes quando indagados a respeito do que é mata ciliar demostram familiaridade com o tema, de forma que antes $73 \%$ dos discentes conheciam a temática e depois $100 \%$. As definições mais abordadas pelos alunos a respeito dessa questão foram: i) é a mata encontrada nas margens dos rios; ii) é a vegetação que fica ao redor dos rios; iii) são árvores e plantas ao redor dos rios; iv) é a cobertura vegetal nas margens dos rios. Verificou-se a eficiência da palestra e do jogo didático, pois depois da aplicação ocorreu um aumento no entendimento da temática abordada, demonstrando que foi ampliado o conhecimento da população pesquisada em relação ao que é mata ciliar.

É válido ressaltar que os alunos já tinham trabalhado com essa temática no ano anterior. Sendo assim, esses dados confirmam o discurso de Nascimento Júnior e Gonçalves (2013), que defendem o uso de jogos didáticos como uma metodologia potencializadora para a EA e afirmam que esses tipos de recursos pedagógicos são ótimos instrumentos para revisão de conteúdos em sala de aula, destacando que este tipo de ferramenta contextualiza e aproxima o indivíduo do seu cotidiano, envolvendo o educando, apresentando diferentes leituras de questões urgentes e essenciais para sua constituição como ser humano no presente. 
De acordo, com Leff (2009), a crise ambiental, é acima tudo, uma questão de compreensão da complexidade do mundo e do próprio ser, tornando-se imprescindível a desconstrução e reconstrução do pensamento, e por meio disso desvendar as origens e compreender causas e as certezas embasadas em pseudo-fundamentos (SOARES et al., 2004). Assim, quando indagados sobre qual a importância ambiental das matas ciliares foi identificado uma reconstrução do pensamento dos discentes, após a IA, ocorrendo um aprimoramento no entendimento da temática trabalhada na palestra. Esse aspecto pode ser observado comparando as respostas dadas por alguns estudantes antes e depois da IA:

\section{Estudante 1:}

Antes da IA: "Pra preservar os rios! Por isso a vegetação preserva os rios.".

Depois da IA: "Para conservar a biodiversidade e evitam diversos processos de degradação.".

Estudante 2:

Antes da IA: "É importante manté-las presevadas, por causa da preservação ambiental".

Depois da IA: "Impede assoreamento, protegendo a qualidade e "higiene" dos rios".

Analisar a percepção ambiental do homem atual é um tarefa muito importante, pois por meio dela é possível identificar quais são as representações sociais dos sujeitos estudados, essas representações demonstram como os sujeitos compreendem e transformam sua realidade, já que são um conjunto de princípios construídos de modo interativo e que são compartilhados pelos grupos sociais (VEIGA et al., 2012, p.72). Nesse sentido, foi possível observar um aprimoramento no conteúdo discurso de alguns discentes depois da intervenção, em relação à percepção ambiental destes, sobre o que acontece quando a mata ciliar se faz ausente. Uma vez que, os educandos se mostraram mais articulados para explicarem o conteúdo utilizando-se inclusive de termos técnicos, como assoreamento, para formular suas respostas.

\section{Estudante 1:}

Antes da IA: "Uma grande porção de terra e lixo cai no rio e acaba secando".

Depois da IA: "As chuvas chegam ao solo com mais força fazendo com que partículas e resíduos do solo poluam o rio".

Estudante 2:

Antes da IA: "Os rios podem secar e acumular lixo".

Depois da IA: "Seca dos rios, assoreamento, enchentes".

A Educação Ambiental (EA), enquanto prática integradora dos processos sociais, origina-se da sensibilidade de unir conhecimento científico, tecnológico, artístico e cultural a uma consciência ambiental inovadora que vise à renovação de valores e do respeito do ser humano para com os recursos naturais, e talvez se tenha com resultado uma dimensão culturalmente 
consciente de atitudes ecológicas (SOARES et al., 2004). Partindo desse pressuposto, os resultados demonstram que a IA também contribuiu na elaboração e reformulação de outros conceitos relacionados à ecologia da mata ciliar, ocorrendo uma evolução substancial nas respostas: i) de $45 \%$ para 95\% de compreensão dos danos ambientais causados com a redução das matas ciliares; ii) de $55 \%$ para $95 \%$ de compreensão de o porquê preservar as matas ciliares; iii) de $0 \%$ para $58 \%$ sobre o que é uma Área de Preservação Permanente (APP); iv) de $28 \%$ para $80 \%$ no entendimento sobre atuação das matas ciliares.

Esses recursos pedagógicos influenciaram na percepção ambiental dos educandos, bem como, em suas representações sociais. Esses dados podem ser notados ao analisar a Tabela 1, onde é possível verificar que após a IA os discentes começaram a associar a melhoria da qualidade e quantidade das águas do rio com a presença das matas ciliares, bem como, houve uma ampliação do conhecimento em relação a outras funções ecológicas da mesma.

Tabela1: Percentual (\%) dos tipos de respostas apresentadas, a respeito de como atuam as matas ciliares, pelos alunos do 3ํano do Ensino Médio de uma Unidade de Ensino, no município de Itapetinga - Bahia, nos questionários inicial e final.

\begin{tabular}{lcc}
\hline Você sabe como atuam as matas ciliares? & Antes da IA & Depois da IA \\
\hline Como filtros & $45 \%$ & $100 \%$ \\
\hline Evitam a erosão e/ou assoreamento & $41 \%$ & $95 \%$ \\
\hline Corredores ecológicos & $38 \%$ & $93 \%$ \\
\hline Protegem os rios & $60 \%$ & $85 \%$ \\
\hline Evitam enchentes & $27 \%$ & $98 \%$ \\
\hline Abrigam e Conservam a Biodiversidade & $25 \%$ & $97 \%$ \\
\hline
\end{tabular}

Em relação às plantas que ocorrem na mata ciliar do Rio Catolé foi perceptível um aumento significativo na identificação das espécies nativas e exóticas após sua aplicação com destaque para: i) de 22\% para 95\% sobre identificar a Algaroba (Prosopis juliflora (Sw.) DC.) como espécie nativa; ii) de $27 \%$ para $98 \%$ sobre identificar Limão (Citrus sp.) como espécie exótica. Conforme Tabela 2.

Sabendo que a Bahia é um estado com grande expansão territorial e variados ambientes naturais, conhecer, descrever e caracterizar as espécies vegetais nativas são de extrema importância para que qualquer projeto de recomposição florestal de mata ciliar seja posto em prática (BAHIA, 2007, p.35). Assim, esse estudo é de grande valia, pois a partir da análise dos dados foi possível observar que o Jogo "Reconquista da Mata Ciliar" foi eficiente no aprendizado da flora local, onde foram realizadas atividades voltadas para a realidade do sujeito respeitando o percurso histórico e cultural do indivíduo (LUCAS et al., 2010). 
Tabela 2: Percentual de acertos apresentados pelos alunos do 3ํano do Ensino Médio de uma Unidade de Ensino, no município de Itapetinga - Bahia, nos questionários inicial e final, a respeito das plantas nativas e exóticas da mata ciliar do Rio Catolé.

\begin{tabular}{lcc}
\hline Espécie de Plantas & Antes da IA & Depois da IA \\
\hline Jureminhab (Desmanthus virgatus (L.) Willd) & $45 \%$ & $100 \%$ \\
\hline Pau-amendoim (Pterogyne nitens Tul.) & $41 \%$ & $95 \%$ \\
\hline Farinha-Seca (Albizia hasslerii Burkart) & $38 \%$ & $93 \%$ \\
\hline Leucena (Leucaena leucocephala de Wit) & $60 \%$ & $85 \%$ \\
\hline Limão (Citrus sp.) & $27 \%$ & $98 \%$ \\
\hline Sarandi (Sebastiania schottiana Müll.Arg) & $25 \%$ & $97 \%$ \\
\hline Aroeira (Schinus terebinthifolius Raddi) & $62 \%$ & $97 \%$ \\
\hline Algaroba (Prosopis juliflora (Sw.) DC.) & $22 \%$ & $95 \%$ \\
\hline Sete-Casca (Calliandra tubulosa Benth) & $33 \%$ & $98 \%$ \\
\hline Olho-de-Boi (Cordia superba Cham.) & $43 \%$ & $93 \%$ \\
\hline Ingazeiro (Inga sp.) & $65 \%$ & $100 \%$ \\
\hline
\end{tabular}

Para BONFIM (2013, p.51-54) os principais impactos ambientais sofridos pelo Rio Catolé e sua mata ciliar são o desmatamento, a deposição de lixo, o assoreamento e o derramamento de esgoto. Nesse quesito esses recursos pedagógicos também contribuíram bastante, já que a frequência de discentes que conseguiram identificar dos processos ambientais sofridos pela mata ciliar do Rio Catolé aumentou, após a aplicação da IA, conforme demonstrado na Figura 3.

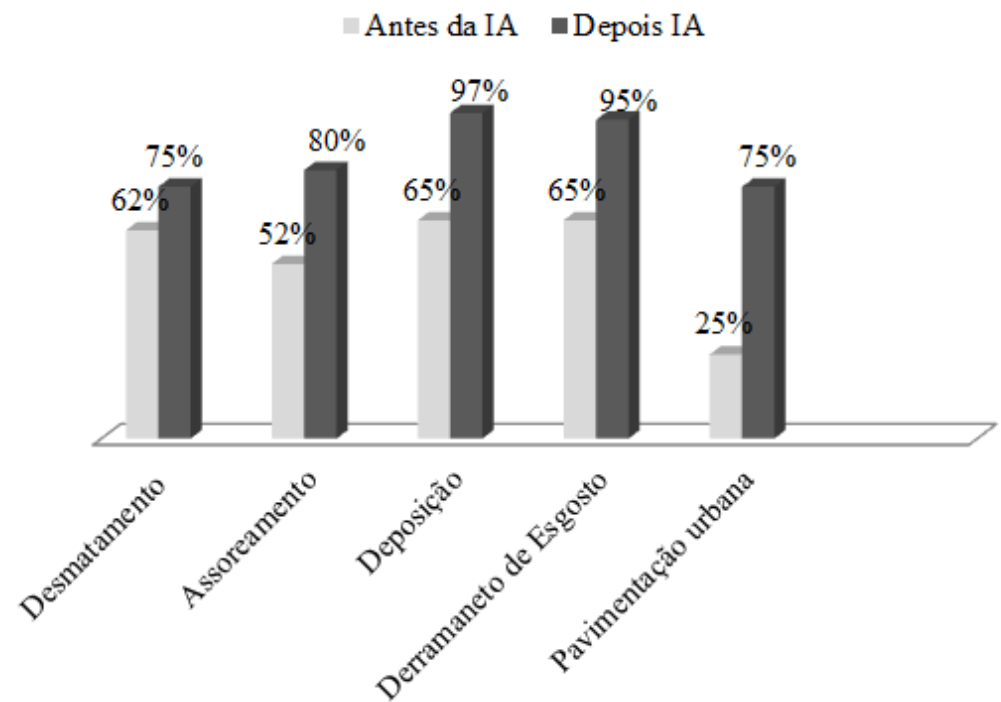

Figura 3: Percentual de discentes, do $3^{\circ}$ ano do Ensino Médio de uma Unidade de Ensino, no município de Itapetinga - Bahia, que conseguiram identificar impactos ambientais que ocorrem no ecossistema mata ciliar do Rio Catolé no município de Itapetinga, nos questionários antes e depois da |Intervenção Ambiental (IA). Fonte: Autoria Própria. 
Portanto, dados como esses realmente explicitam o quando é importante que a educação ambiental seja trabalhada em sala de aula, principalmente quando esta é voltada para a realidade dos educandos, pois promovem a consciência ambiental a partir do momento em que estes reconhecem os processos de degradação dos ecossistemas e sua relação coma falta de qualidade de vida da sociedade (HAMMES, 2004).

Além disso, por meio desses resultados pôde-se observar que as ferramentas utilizadas nesse estudo auxiliaram no processo de ensino aprendizagem, onde o ambiente escolar se destacou como um local adequado para que a educação ambiental fosse trabalhada, propiciando 0 desenvolvimento de conhecimentos, habilidades que levaram a aquisição de valores necessários para lidar com questões ambientais e propor soluções sustentáveis (TONNUS; GARCIA, 2008, p.184)

\section{Conclusões}

Por meio desses resultados foi possível constatar que a Intervenção IA estimulou a aprendizagem, aprofundando os conteúdos, proporcionando elaboração e reformulação de outros conceitos relacionados à ecologia da mata ciliar, ocorrendo uma evolução substancial nas respostas. Dessa forma, o "Jogo Reconquista da Mata Ciliar" possuiu um valor significativo, enquanto objeto educacional e pedagógico, sendo eficiente na construção do conhecimento científico e prazeroso aos discentes, de forma que será fornecido para a escola pesquisada o jogo para ser utilizado como estratégia lúdica. Este trabalho pode auxiliar em estudos sobre as seguintes temáticas: i) Execução de programas de reflorestamento na APP "mata ciliar do Rio Catolé" no município de Itapetinga; ii) Educação Ambiental na Mata Ciliar do Rio Catolé e iii) Estruturação de projetos políticos pedagógicos das escolas do município que visem conscientizar os alunos a respeito dessa temática.

\section{Agradecimentos}

À Universidade Estadual do Sudoeste da Bahia, por tornar possível a Especialização em Meio Ambiente e Desenvolvimento da autora. À Unidade de Ensino do Município de Itapetinga (BA), bem como, os discentes e docentes, por aceitarem e permitirem fazer parte dessa pesquisa.

\section{Referências}

ALVES, A. T. J. et al. D. Reciclagem: Educar para Conscientizar. Anais do II Seminário Interinstitucional de Ensino, Pesquisa e Extensão. UNICRUZ. 2012.

BAHIA. Secretaria de Meio Ambiente e Recursos Hídricos - Semarh. Recomposição Florestal de Matas Ciliares. Salvador: Gráfica Print Folhes, 3.ed.rev. e ampl. 2007. 
BITTENCOURT, L.F.F.; BATISTA, G. T. Intervenção Humana na Mata Ciliar do Rio Paraíba do Sul, Município de Caçapava, SP. OKARA: Geografia em debate. v.3, n.2, p. 254-270, 2009.

BRASIL. Secretaria de Educação Fundamental. Parâmetros curriculares nacionais: apresentação dos temas transversais, meio ambiente / Secretaria de Educação Fundamental. - Brasília: MEC/SEF, 1997. Disponível em:<http://www.portal.mec.gov.br/seb/arquivos/pdf/ivro091.pdf> Acesso em: 15 set. 2016.

BONFIM, D.J. Análise do uso e ocupação da mata ciliar do rio Catolé em Itapetinga (BA) como subsidio para a educação ambiental. Monografia (Graduação em Licenciatura e Ciências Biológicas), Universidade Estadual do Sudoeste da Bahia-UESB, Itapetinga/BA. 2013.

CAREGNATO, R.C.A.; MUTTI, R. Pesquisa qualitativa: análise de discurso versus análise de conteúdo. Florianópolis: 2006. Texto Contexto Enfermagem.

FORTUNA, T.R. Jogo em aula: Recurso permite repensar as relações de ensino-aprendizagem; Revista do professor. Porto alegre. 2003.

HAMMES, V.S. Construção da Proposta Pedagógica. Volume 1/Embrapa. Editora Globo. 2004.

LEANDRO, M.D.; VIVEIROS, C.A.F. Mata Ciliar, Área de Reserva Permanente. Linha Direta. 2003.

LEFF, E. (Coord.). A complexidade ambiental. São Paulo: Cortez, 2003.

LUCAS, F.C.A. et al. 2010.Ações em Educação Ambiental para crianças e adolescentes da Vila da Barca em Belém/PA: uma proposta de conscientização. Educação Ambiental em Ação, n. 34, ano 9.

MENEZES, I.S. Uma Abordagem Lúdica no ensino de Botânica: análise dos jogos didáticos na construção do conhecimento. (Monografia - Curso de Licenciatura em Ciências Biológicas). Itapetinga- BA: UESB. 2012.

NASCIMENTO JÚNIOR, A.F.N. GONÇALVES, L.V. Oficina de jogos pedagógicos de ensino de ecologia e educação ambiental como estratégia de ensino na formação de professores. Revista Práxis, ano V, nำ. UFLA, Lavras, MG. 2013.

OLIVEIRA, A.L. et al.. A. Educação ambiental: concepções e práticas de professores de ciências do ensino fundamental. Revista Electrónica de Enseñanza de las Ciencias Vol. 6, №3, 471-495. Universidade Estadual de Maringá. Brasil. 2007.

OLIVEIRA, M.M. Diversidade de anuros no Parque Municipal da Matinha, em Itapetinga, Bahia. Dissertação (Mestrado em Ciências Ambientais) Curso de Pós-Graduação em Ciências Ambientais da Universidade Estadual do Sudoeste da Bahia - UESB - Campus de Itapetinga. - Itapetinga: UESB, 2013. 
PAZ, R.J.; FARIAS, T. (Organizadores). Gestão de áreas protegidas: processos e casos particulares. João Pessoa: Universitária/UFPB, 2008.

SACRAMENTO, et al. Análise da Interdisciplinaridade e Transversalidade da Educação Ambiental no Ensino Médio da Rede Estadual do Rio de Janeiro: Um Estudo de Caso. Anais do Encontro Nacional de Ensino de Ciências da Saúde e do Ambiente. UNIPLI, Niterói-RJ. 2008.

SILVA, D.M.C. GRILLO, M. A Utilização dos Jogos Educativos como Instrumento de Educação Ambiental: O Caso da Reserva Ecológica de Gurjaú - PE. Contrapontos, vol.8, no 2. p. 229 - 238. UFLA - Universidade Federal de Lavras, Lavras, MG. 2008.

SOARES, A.M.D.; OLIVEIRA, L.M.T.; PORTILHO, E.S.; CORDEIRO, L.C.; CAVALCANTE, D.K. Educação Ambiental: Construindo Metodologias e Práticas Participativas. Anais do II Encontro da ANPPAS. Indaiatuba - São Paulo - Brasil. 2004.

TANNOUS, S.; GARCIA, A. Histórico e evolução da educação ambiental, através dos tratados internacionais sobre o meio ambiente. Nucleus. Ituverava. v.5, n.2, p. 183-195, 2008.

VEIGA, A.A.A. et al. Diferentes Olhares e Ações para a Educação Ambiental: Um Exercício de Cidadania num Projeto de Extensão. Revbea, V. 7, № 2. Rio Grande. 67-76, 2012. 